\title{
Liver lesions found at colectomy in ulcerative colitis: correlation between histological findings and biochemical parameters
}

\author{
J Mattila, P Aitola, M Matikainen
}

\begin{abstract}
Aims-To classify lesions discovered at colectomy in patients with ulcerative colitis; to assess the importance of histological findings by correlating them with biochemical parameters.

Methods-Liver tissue specimens taken at colectomy from 59 patients with chronic ulcerative colitis were studied using light microscopy. The findings were compared with results of biochemical liver function tests.

Results-Abnormal laboratory findings were found in 12 patients with liver histology consistent with primary sclerosing cholangitis. Non-specific reactive hepatitis was observed in six patients, eight had fatty liver, and three minor non-specific parenchymal changes. Twenty nine patients had normal liver histology. The highest cholestatic serum enzyme activities were seen in two patients with sclerosing cholangitis. Cholangiography in these patients also revealed changes in the extrahepatic bile ducts. However, identical histological changes were also present in patients with only slightly abnormal or even normal liver enzyme activities.

Conclusion-Biochemical tests of liver function do not reliably indicate the extent or severity of bile duct damage in ulcerative colitis, the assessment of which requires liver biopsy.
\end{abstract}

$(\mathfrak{F}$ Clin Pathol 1994;47:1019-1021)

A wide range of hepatic histological abnormalities have been reported in up to $94 \%$ of patients with ulcerative colitis. ${ }^{1}$ However, clinically important diseases such as primary sclerosing cholangitis (PSC) or bile duct carcinoma have been reported in only 5 to $10 \%$ of these patients. ${ }^{2}$ The former is characterised by chronic fibrosing inflammation of bile ducts involving the entire extrahepatic and intrahepatic system or any segment thereof. The diagnosis is usually based on a combination of clinical, biochemical, and radiological abnormalities. ${ }^{3}$

Within the liver, small and large duct disease may occur independently. ${ }^{4}$ For the diagnosis of small duct PSC, liver biopsy is the most useful procedure in that the small bile ducts cannot be seen on cholangiography. ${ }^{5}$ Recently, the hepatic histology of PSC has been described in great detail, and a staging system has been proposed as a more effective means of predicting disease progression. ${ }^{6}$

Biochemical dysfunction of the liver has been reported in $15 \%$ of patients with ulcerative colitis. ${ }^{7}$ An increase in the serum activity of alkaline phosphatase is the most useful biochemical marker of bile duct damage. ${ }^{8}$

The aim of this study was to classify histologically lesions discovered at colectomy in patients with ulcerative colitis and to assess the clinical relevance of these findings by correlating them with biochemical parameters of liver tissue damage.

\section{Methods}

Liver wedge biopsy specimens, taken at colectomy in consecutive patients with ulcerative colitis during 1982-1987 at Tampere University Hospital, were analysed.

The study population comprised 59 patients (25 women and 34 men) aged from 20 to 75 years (median 38 years). Some of these patients had been included in an earlier study of ultrastructural features of PSC. ${ }^{9}$ Duration of disease ranged from $0 \cdot 1$ to 28 years (mean 6.4 years). The whole colon was affected in 51 patients, while colitis was present in the left colon only in the other eight. Endoscopic retrograde cholangiography (ERC) was indicated in only two patients with jaundice. Cholangiography was carried out intraoperatively at cholecystectomy in three patients. The study was approved by the ethical committee of Tampere University Hospital and informed consent was obtained from all patients.

Serum alkaline phosphatase, $\gamma$-glutamyl transferase (GGT) activities and bilirubin concentrations were used as markers of cholestasis, and alanine aminotransaminase (ALT) and aspartate aminotransaminase (AST) activities as indicators of hepatocytic damage. Specimens were taken before the patients underwent surgery.

Wedge liver biopsy specimens obtained at colectomy were fixed in $10 \%$ buffered formalin, embedded in paraffin wax, and sectioned $(5 \mu \mathrm{m})$. The sections were stained with haematoxylin and eosin, chromotrope aniline blue, and Prussian blue for iron.

Liver biopsy specimen results were reported without knowledge of the biochemical or radiological findings.

The criteria can be summarised as follows: (1) Normal portal area: The normal portal area has few inflammatory cells, and one to three terminal bile ducts surrounded by 
Biochemical liver function test results in 59 patients with ulcerative colitis. Results expressed as median (range)

\begin{tabular}{|c|c|c|c|c|c|c|}
\hline $\begin{array}{l}\text { Liver } \\
\text { histolgy }\end{array}$ & $\begin{array}{l}\text { Number of } \\
\text { patients }\end{array}$ & $A L P$ & $G G T$ & $A L T$ & $A S T$ & Bilirubin \\
\hline $\begin{array}{l}\text { Normal } \\
\text { Fatty liver } \\
\text { Non-specific reactive hepatitis } \\
\text { Miscellaneous abnormalities } \\
\text { Lymphoid cholangitis } \\
\text { Pleomorphic cholangitis } \\
\text { Fibrous cholangitis }\end{array}$ & $\begin{array}{r}29 \\
9 \\
6 \\
3 \\
3 \\
2 \\
7\end{array}$ & $\begin{array}{l}150(70-210) \mathrm{n}=22 \\
143(88-199) \mathrm{n}=7 \\
201(139-252) \mathrm{n}=4 \\
136(128-144) \mathrm{n}=2 \\
236(159-331) \mathrm{n}=3 \\
239(174-304) \mathrm{n}=2 \\
631(166-1889) \mathrm{n}=7\end{array}$ & $\begin{array}{l}29(13-62) n=11 \\
27(22-35) n=4 \\
64(19-116) n=3 \\
- \\
157 n=1 \\
30 n=1 \\
268(53-587) n=4\end{array}$ & $\begin{array}{l}18(5-115) \mathrm{n}=23 \\
25(15-44) \mathrm{n}=4 \\
25(11-45) \mathrm{n}=4 \\
42(20-63) \mathrm{n}=2 \\
37(11-60) \mathrm{n}=3 \\
39(24-53) \mathrm{n}=2 \\
83(17-159) \mathrm{n}=7\end{array}$ & $\begin{array}{l}12(12-28) n=21 \\
25(16-42) n=5 \\
26(12-35) n=3 \\
24(19-28) n=2 \\
26(15-40) n=3 \\
20(16-24) n=2 \\
46(27-94) n=6\end{array}$ & $\begin{array}{l}7(2-23) \mathrm{n}=11 \\
7(3-10) \mathrm{n}=5 \\
7(3-10) \mathrm{n}=4 \\
6 \mathrm{n}=1 \\
5 \mathrm{n}=1 \\
9(5-13) \mathrm{n}=2 \\
11(4-32) \mathrm{n}=7\end{array}$ \\
\hline
\end{tabular}

The reference values for biochemical tests are the normal ranges given by the Department of Clinical Chemistry, Tampere University Hospital, Tampere, Finland. ALP = alkaline phosphatase $(60-275 \mathrm{U} / \mathrm{l}) ; \mathrm{ALT}=$ alanine aminotransaminase $(0-39 \mathrm{U} / \mathrm{l}) ; \mathrm{AST}=$ aspartate aminotransaminase $(0-40 \mathrm{U} / \mathrm{l}) ; \mathrm{GGT}=\gamma$ glutamyl transferase $(0-50 \mathrm{U} / \mathrm{l})$; Bilirubin $(20 \mu \mathrm{m} / \mathrm{l})$.

basement membrane; however, the larger interlobular branches have a fibromuscular wall.

(2) Non-specific reactive hepatitis: Inflammatory lympho-histiocytic cells in portal areas may vary from one portal area to another. Distribution of inflammatory cells not associated with bile ducts in portal areas is often patchy. Bile ducts are normal and slight fibrous replacement of lymphoid tissue may be present.

(3) Cholangitis: Classification and staging of cholangitis were based on the criteria of Ludwig et al. ${ }^{6}$ Briefly, lymphoid cholangitis was defined as lymphocytic infiltration surrounding bile ducts and ductal proliferation with or without atypical bile duct cells. Pleomorphic cholangitis was defined as a mixed inflammatory infiltrate in the wall of interlobular or septal bile ducts. Inflammatory bile duct lesions are also evident. Fibrous cholangitis was defined as a fibrous collar of bile ducts with few inflammatory cells, irregularity of bile duct epithelium and possible absence of bile ducts.

Staging was defined as follows: Stage I (portal stage), inflammation and abnormalities of bile ducts confined to portal tracts; stage II (periportal stage), inflammed periportal areas with fibrosis or ductal proliferation; stage III (septal stage), septal fibrosis or bridging necrosis, and stage IV (cirrhotic stage), biliary cirrhosis. The hepatic abnormalities in PSC were subdivided into early stages I-II, or late stages III-IV.

\section{Results}

Liver biopsy specimens from 29 patients were normal on light microscopy; nine had mild to moderate fatty change, six had non-specific reactive hepatitis, and three had only minor histological abnormalities such as glycogen nuclei. Histological features consistent with PSC were found in 12 of the 59 (22\%) patients. The type and stage of small duct PSC were as follows: three patients had lymphoid cholangitis (stage I), two had pleomorphic cholangitis (stage II), and seven fibrous cholangitis (stages I-II). Two of the latter patients had chronic cholestatic liver disease. Both had large bile duct alterations on ERC. At cholecystectomy, performed intraoperatively on three patients, the cholangiographs were normal. One of these patients had pleomorphic cholangitis (stage II), one had normal liver histology, and one mild fatty liver.
The latter patient also had mild persistent abnormalities in liver function tests.

The correlation between the histological findings and biochemical test results are presented in the table.

Cholestatic enzyme activities, alkaline phosphatase and GGT, were within the normal range in all patients with normal liver histology, fatty liver, and in five cases of non-specific reactive hepatitis. Alkaline phosphatase activities were slightly raised in one patient with lymphoid and one with pleomorphic cholangitis, and slightly to noticeably raised in all but two of the patients with fibrous cholangitis. GGT activities were slightly raised in one patient with non-specific reactive hepatitis and in another with lymphoid cholangitis, and slightly or noticeably increased in four patients with fibrous cholangitis. The activity appeared to rise in parallel with increases in alkaline phosphatase activities. Increased ALT activities occurred in three patients with fibrous cholangitis and in one patient with normal liver histology. Bilirubin concentrations were normal in all patients.

\section{Discussion}

The morphological classification of PSC in this study was based on that devised by Ludwig et al. ${ }^{6}$ Clinically evident cholestatic liver disease and radiological alterations in large bile ducts compatible with PSC were seen in two patients with fibrous cholangitis, who had the highest enzyme activities indicative of cholestasis. We did not find it reasonable or acceptable to perform an ERC on every patient, because, despite its clinical usefulness, serious complications such as infection can occur. ${ }^{1011}$ It is worth noting that intrahepatic, small duct PSC can occur in the absence of extrahepatic large duct PSC.

Histology is the only means of diagnosing small duct disease because small bile ducts seen at biopsy are too small for cholangiographic demonstration and, therefore, ERC will be negative. ${ }^{5}$ Small duct PSC, however, may be the earliest manifestation of PSC and indicative of a transition from a pattern of small to large duct disease. ${ }^{12}$ Wee and Ludwig ${ }^{4}$ reported ERC negative, small duct PSC in up to $30 \%$ of their patients with ulcerative colitis.

Normal laboratory test values were seen in one patient with fibrous (stage I), two with lymphoid (stage I), and one with pleomorphic 
(stage II) disease. Slightly raised alkaline phosphatase or GGT, or both, activities were seen in one patient with lymphoid (stage II) and four with fibrous (stages I-II) disease.

During the early phases of histological cholangitis, functional evidence of cholestasis may be mild. Increased ALT activities indicative of acute hepatocyte damage were seen in only two patients with fibrous cholangitis and in one with normal histology. One of the six non-specific reactive hepatitis cases had slightly raised GGT activities. Both GGT and ALT activities are increased in all forms of liver damage, often because of induction. Bilirubin concentrations were normal in all patients, and because of the focal nature of bile duct lesions, bilirubin concentrations do not always increase in the early stages of the disease process.

Non-specific reactive hepatitis, which may be seen as a physiological response to either intra- or extrahepatic disorders, is not a disease in itself. ${ }^{13}$ Chronic hepatitis B virus could be excluded because hepatitis $B$ virus antigens (HBsAG, HBcAG) were not expressed in liver tissue. On the other hand, chronic hepatitis $C$ virus could not be ruled out because a specific serological test was not available. This seems unlikely, however, because the patients were clinically asymptomatic and had normal serum transaminase activities. Also, none of the patients had ever received a blood transfusion.

In patients with ulcerative colitis the use of ERC together with biochemical screening of serum alkaline phosphatase activity has resulted in an increase in the incidence of liver disease diagnosis. However, because liver function test results may be normal in the presence of severe bile duct changes, such as those seen in our study and also reported by others, ${ }^{712} 14$ and because a significant amount of PSC may be of the small duct type, confined to the intrahepatic biliary tree without the characteristic cholangiographic and clinical manifestations, liver biopsy would seem to be an appropriate means of classifying liver lesions, particularly for identifying early bile duct lesions.

1 Eade MN. Liver disease in ulcerative colitis. Ann Intern Med 1970;72:475-82.

2 Kern F. Extraintestinal complications. In: Kirsner JB, Shorter RG, eds. Inflammatory bowel disease, 2nd edn. Philadelphia: Lea and Febiger, 1980:217-27.

3 LaRusso NF, Russel H, Ludwig J, MacCarty RL. Primary sclerosing cholangitis. $N$ Engl F Med 1984;310:899-903.

4 Wee A, Ludwig J. Pericholangitis in chronic ulcerative colitis: primary sclerosing cholangitis of the small bile ducts? Ann Intern Med 1985;102:581-7.

5 Ludwig J. Surgical pathology of the syndrome of primary sclerosing cholangitis. Am $₹$ Surg Pathol 1989;13(Suppl 1):43-9.

6 Ludwig J, LaRusso F, Wiesner RH. Primary sclerosing cholangitis. In: Peters LR, Craig R, eds. Liver pathology. New York: Churchill Livingstone, 1986:193-213.

7 Perrett AD, Higgins G, Johnston HH, Massarella GR, Truelove SC, Wright R. The liver in ulcerative colitis. Truelove SC, Wright R.

8 Dew MJ, Thompson $\mathbf{H}$, Allan R. The spectrum of hepatic dysfunction in inflammatory bowel disease. $Q \mathcal{F}$ Med 1979;48:1 13-35.

9 Mattila J, Pitkänen R, Halonen P, Matikainen $M$. Ultrastructural aspects of liver injury with special reference to small bile ducts in patients with ulcerative colitis. Liver 1992;12:155-60.

10 Deviere J, Motte S, Dumonceau JM, Serruys E, Thys JP, Cremer $M$. Septicemia after endoscopic retrograde cholangiopancreatography. Endoscopy 1990;22:72-5.

11 Sauter G, Grabein B, Huber G, Mannes GA, Ruckdeschel G, Sauerbruch T. Antibiotic prophylaxis of infectious complications with endoscopic retrograde cholangiopancomplications with endoscopic retrograde cholangiopancreatography. A

12 Wiesner RH, Ludwig J, LaRusso NF, MacCarty RL. Diagnosis and treatment of primary sclerosing cholangitis. Semin Liver Dis 1985;5:241-53.

13 Popper H, Schaffiner F. Liver: Structure and Function. New York: McGraw-Hill, 1957:404-7.

14 Balasubramaniam K, Wiesner RH, LaRusso NF. Primary sclerosing cholangitis with normal serum alkaline phosphatase activity. Gastroenterology 1988;95:1395-8. 